\title{
Foreign Body or Foreign Bodies
}

\author{
Samet Ozer ${ }^{\mathrm{a}, \mathrm{d}}$, Resul Yilmaza, Fevzi Ataseven ${ }^{\mathrm{b}}$, \\ Atilla Senaylic
}

\begin{abstract}
Foreign body ingestion is a common complaint in the pediatric emergency department and a common problem throughout the world. Here, we report an interesting case of a coin ingestion in which the radiographic findings misguide the clinician. Foreign objects attach frequently esophagus anatomic narrowness. They must be taken out immediately because they can cause an obstruction, mucosal erosion or perforation. Endoscopy is the criterion standard for removal of foreign bodies from the esophagus. Foley and bougienage techniques are the other methods. In this case we presented a clinical condition that is seen and thought only a foreign object like a coin by the direct graphy. After it was taken out by the Foley catheter, that was seen there was more than one foreign body which were coins.
\end{abstract}

Keywords: Foreign body; Children; Coins

\section{Introduction}

Swallowing a foreign body in childhood is frequently seen condition in pediatric emergency departments. Majority of patients are under 5 years and $70 \%$ of them are under 3 years $[1,2]$. These children usually complain with a variety of gastrointestinal (GI), respiratory, or nonspecific symptoms including choking, drooling, poor feeding, fever, wheezing, stridor, vomiting, dysphagia, odynophagia, chest, throat,

\footnotetext{
Manuscript accepted for publication August 18, 2014

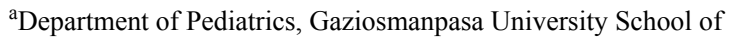
Medicine, Tokat, Turkey

${ }^{b}$ Department of Pediatrics, 19 Mayis University School of Medicine, Samsun, Turkey

'Pediatric Surgery Department, Ankara Children's Hematology and Oncology Research and Training Hospital, Ankara, Turkey

${ }^{\mathrm{d} C}$ Corresponding Author: Samet Ozer, Department of Pediatrics, Gaziosmanpasa University School of Medicine, 60030 Tokat, Turkey. Email: sozerdr@hotmail.com
}

or even neck pain [3]. According to the coronal viewpoint esophageal foreign bodies can stand on cricopharyngeal level. Foreign bodies tend to lodge in sites of constriction in the esophagus. These are usually the points of natural narrowing of esophagus [4]. Esophageal coins usually lodge in the upper esophageal sphincter/thoracic inlet (60-70\%), mid-esophagus at the level of the aortic notch (10-20\%), and above the lower esophageal sphincter (20\%) [5]. The most seen foreign bodies in children are coins and more dangerous one is button batteries. Since coins have thin and circular structure, they are swallowed easily. Swallowing coins is rarely seen with complications. Treatment approach differs according to foreign body's shape, size, content, swallowed time and the location $[6,7]$.

It is decided that to take out the foreign body by the Foley catheter since it has not passed the upper esophageal sphincter. Literature knowledge was applied and this procedure has discussed when two foreign bodies were met.

\section{Case Report}

A girl 3.5 years old was admitted to pediatric emergency service with sore throat, swallowing difficulty and discomfort. The child's parents recall she had ingested a round object and it is learned that she swallowed coin $4 \mathrm{~h}$ ago while she was playing with her brother. Her vital signs were normal. The oxygen saturation was $98 \%$. Her motor and mental evaluation was normal and there was no pathologic evidence in physical examination. Chest radiography showed that there was a foreign body like coin on upper esophagus. Since there was only one coin image standard application which is Foley catheter method was used to take out the foreign body. It is seen that there were two foreign bodies. One of them was bigger than the other one. All foreign bodies were taken out from upper esophagus. The patient was discharged from hospital at same day with no complication.

\section{Discussion}

Swallowing foreign body is a cause of children mortality 
aged 1 - 3 and mortality rate is $7 \%$. Respiratory tract crash, atelectasia, bronshiectasia and pneumonia are other serious complications of foreign body swallowing. Because of mortality and the morbidity patients who admitted to emergency service with the probality of aspiration foreign body must be evaluated as soon as possibly $[1,2]$.

Most of the children are under 5 years old who swallow foreign body. Swallowed foreign bodies can be observed for development of symptoms, as $80 \%$ of foreign bodies which reach the stomach spontaneously pass. Only $12 \%$ of patients required operation, and no mortality was seen [8]. As a clinical finding $22 \%$ of foreign bodies attach to lower esophageal segment [9]. The foreign bodies are generally coin, pin, toy pieces, circular objects, disc-shaped batteries, amulet, osicles and other small objects $[5,6]$. Most of the swallowed foreign bodies vary to geographic characteristics. These foreign bodies attach to beginning of esophagus, where the esophagus crosses the arcus aorta and crosses main left bronsch and passes the diaphragm [10]. All of the foreign bodies must be taken out by endoscopic method or Foley catheter method, because all of them may cause obstruction, mucosa erosion or perforation [9].

It is reported that foreign bodies in the esophagus may be wrongly diagnosed by radiologic screening. It was reported as a coin but after taken out it was seen that was a battery-shaped button [11]. Also it was reported more than one foreign body was seen in GI system. According to literature review there was not reported two foreign bodies on upper esophagus like our patient. In this case, in the first evaluation there is only one coin in upper esophagus on chest radiography. After taken out by Foley catheter it was seen that there were two coins and one of them was on the other one. Bigger one is $18 \mathrm{~mm}$ and the other is $16 \mathrm{~mm}$.

\section{Conclusion}

There may be more than one foreign body probability when Foley catheter application was conducted. The other foreign bodies can be different from the coins. Because of the fact that Foley catheter may increase the morbidity risk. Because of this not only taking an anterior posterior graphy but also a lateral graphy may be necessary. Whatever this condition is rarely seen.

\section{Author Notes}

Fevzi Ataseven and Atilla Senayli's past affiliation was Department of Pediatrics, Gaziosmanpasa University School of Medicine, Tokat, Turkey, where this work was primarily carried out.

\section{References}

1. Lemberg PS, Darrow DH, Holinger LD. Aerodigestive tract foreign bodies in the older child and adolescent. Ann Otol Rhinol Laryngol. 1996;105(4):267-271.

2. Guelfguat M, Kaplinskiy V, Reddy SH, DiPoce CJ. Clinical guidelines for imaging and reporting ingested foreign bodies. AJR Am J Roentgenol. 2014;203(1):37-53.

3. Chen MK, Beierle EA. Gastrointestinal foreign bodies. Pediatr Ann. 2001;30(12):736-742.

4. Kaur A, Singh A, Singal R, Singh M, Gupta S. An unusual foreign body in the cricopharynx; first case report managed endoscopically. J Med Life. 2013;6(1):65-67.

5. Kay M, Wyllie R. Pediatric foreign bodies and their management. Curr Gastroenterol Rep. 2005;7(3):212-218.

6. Sahn B, Mamula P, Ford CA. Review of Foreign Body Ingestion and Esophageal Food Impaction Management in Adolescents. J Adolesc Health. 2014;55(2):260-266.

7. Gu Q, Fan J, Li J, He G. [Clinical analysis of esophageal perforation and neck abscess induced by esophageal foreign body]. Lin Chung Er Bi Yan Hou Tou Jing Wai Ke Za Zhi. 2014;28(7):459-461.

8. Selivanov V, Sheldon GF, Cello JP, Crass RA. Management of foreign body ingestion. Ann Surg. 1984;199(2):187-191.

9. Jafari SA, Khalesi M, Partovi S, Kiani M, Ahanchian $\mathrm{H}$, Kianifar H. Ingested Foreign Bodies Removed by Lexible Endoscopy in Pediatric Patients: A 10year Retrospective Study. Iran J Otorhinolaryngol. 2014;26(76):175-179.

10. Rovin JD, Rodgers BM. Pediatric foreign body aspiration. Pediatr Rev. 2000;21(3):86-90.

11. Silverberg M, Tillotson R. Case report: esophageal foreign body mistaken for impacted button battery. Pediatr Emerg Care. 2006;22(4):262-265. 